\title{
PLANO DE CUIDADOS COMPARTILHADO JUNTO A CLIENTES ESTOMIZADOS: A PEDAGOGIA FREIREANA E SUAS CONTRIBUIÇÕES À PRÁTICA EDUCATIVA DA ENFERMAGEM ${ }^{1}$
}

\author{
Paula Alvarenga de Figueiredo Martins², Neide Aparecida Titonelli Alvim ${ }^{3}$
}

\begin{abstract}
1 Artigo-excerto da dissertação - Compartilhando saberes e práticas com clientes estomizados acerca da manutenção da estomia de eliminação: uma proposta educativa do cuidado de enfermagem no contexto ambulatorial, apresentada ao Programa de Pós-Graduação da Escola de Enfermagem Anna Nery (EEAN), da Universidade Federal do Rio de Janeiro (UFRJ), em 2010. Apoio financeiro da CAPES e da Fundação de Amparo à Pesquisa do Estado do Rio de Janeiro.

${ }^{2}$ Doutoranda em Enfermagem pela EEAN/UFRJ. Professora Assistente do Curso de Enfermagem da Universidade Iguaçu e Faculdade Metropolitana São Carlos. Rio de Janeiro, Brasil. E-mail: eaepaula@yahoo.com.br

${ }^{3}$ Doutora em Enfermagem pela EEAN/UFRJ. Professora Associado do Departamento de Enfermagem Fundamental da EEAN/ UFRJ. Bolsista de produtividade do CNPq. Rio de Janeiro, Brasil. E-mail: titonelli@globo.com
\end{abstract}

RESUMO: Pesquisa qualitativa, objetivando conhecer o compartilhamento de saberes e práticas de clientes estomizados sobre a manutenção da estomia de eliminação intestinal e urinária no contexto ambulatorial, e discutir suas possíveis repercussões no contexto domiciliar. Os sujeitos foram 17 clientes adultos e idosos estomizados em acompanhamento ambulatorial no município de Campos dos Goytacazes-RJ. Aplicou-se a abordagem metodológica Pesquisa Convergente-Assistencial e a análise de conteúdo temática. A confecção do plano de cuidados foi o produto instituído mediante a troca de experiências e saberes no ambulatório, tendo sido a pedagogia problematizadora instrumento facilitador na aprendizagem de clientes estomizados, durante o processo educativo. Com o retorno dos clientes no ambulatório, foi possível denotar os sucessos derivados da pedagogia utilizada. Sua condição de crítica e reflexão tornou-se aguçada, exercendo com maior segurança e autonomia os cuidados relacionados à manutenção de sua estomia, avaliando, modificando hábitos e transformando a realidade.

DESCRITORES: Enfermagem. Cuidados de enfermagem. Educação em saúde. Estomia.

\section{CARE PLAN SHARED WITH OSTOMIZED CLIENTS: FREIRE'S PEDAGOGY AND ITS CONTRIBUTIONS TO NURSING EDUCATION PRACTICE}

\begin{abstract}
The aim of this qualitative research was to get to know the sharing of knowledge and practices with ostomized clients on intestinal and urinary elimination stoma maintenance in the outpatient context, and to discuss its possible repercussions in the home context. The subjects were 17 adult and elderly ostomized clients under outpatient follow-up in Campos dos Goytacazes - Rio de Janeiro. The Convergent Care Research method and thematic content analysis were applied. The confection of the care plan was the product obtained through experience and knowledge exchange at the clinic. During the education process, the problematizing pedagogy facilitated the ostomized clients' learning. When the clients returned to the clinic, the success deriving from the adopted pedagogy could be observed. Their critical and reflexive conditions were sharpened, practicing stoma maintenance care with more security and autonomy, at the same time as they assessed and modified habits and transformed reality.
\end{abstract}

DESCRIPTORS: Nursing. Nursing care. Health education. Ostomy.

\section{PLAN DE CUIDADOS COMPARTIDOS JUNTO A LOS CLIENTES OSTOMIZADOS: PEDAGOGÍA FREIREANA Y SUS CONTRIBUCIONES A LA ENFERMERÍA PRÁCTICA EDUCATIVA}

RESUMEN: Investigación cualitativa, objetivando conocer el intercambio de conocimientos y prácticas de clientes ostomizados sobre el manejo de la ostomía y la eliminación intestinal y urinaria en el contexto ambulatorio, y discutir las posibles repercusiones en el contexto domiciliar. Los sujetos fueron 17 clientes adultos y ancianos ostomizados bajo seguimiento ambulatorio en el municipio de Campos dos Goytacazes-RJ. Se utilizó un abordaje metodológico de pesquisa convergente-asistencial y un análisis del contenido temático. La realización del plan de atención fue producto del intercambio de experiencias y conocimientos en la clínica, siendo el facilitador en la solución de problemas de aprendizaje, el clientes ostomizado. Con el regreso de los clientes en el ambulatorio se pudo denotar los éxitos derivados de la pedagogía utilizada en el proceso educativo. Su pensamiento crítico y reflectivo se agudizó; ejerciendo con mayor seguridad y autonomía los cuidados relacionados manejo de su ostomía, evaluando, modificando hábitos y transformando la realidad. DESCRIPTORES: Enfermería. Atención de enfermería. Educación en salud. Estomía. 


\section{INTRODUÇÃO}

No ambulatório em que tivemos a oportunidade de prestar cuidados ao cliente estomizado, observamos que as ações de educação em saúde, quando realizadas pelo enfermeiro, quase sempre se configuravam de maneira verticalizada, unidirecional, caracterizadas pelo modelo tradicional de educação depositária, constituindo em ações voltadas para o cliente e não "com" o cliente, resultando em um cuidado dominante, que impõe práticas instituídas oficialmente através da cultura científica. ${ }^{1}$

Estudo realizado no Estado de São Paulo, que objetivou identificar o nível de conhecimento do cliente colostomizado sobre o seu cuidado, para prevenção de possíveis complicações, mostrou que $100 \%$ dos clientes dele participantes, não sabiam o que era uma colostomia e concordavam com a importância do treinamento para o cuidado de si. ${ }^{2}$

Na condição de educadora em saúde, a enfermeira precisa conhecer a realidade na qual se situa o cliente, devendo resgatar esse sujeito como cidadão participante do seu processo de cuidado, através do diálogo, possibilitando desta forma, a transição de uma consciência ingênua, caracterizada pela passividade, para uma consciência crítica e reflexiva, capaz de colocá-lo em posição questionadora, participativa e ativa. Isto significa que os clientes devam assumir a posição de sujeitos e não objetos da ação profissional. Assim agindo, podem optar por aderir ou não à mudança de hábitos, atitudes e modos de pensar a vida e a saúde. Desta maneira, a enfermeira constrói conjuntamente com os clientes os possíveis caminhos, podendo os mesmos, ou escolher a mudança, que ocorre no sentido da verdadeira humanização do homem, ou ficar a favor da permanência, chegando ao ápice da antimudança. ${ }^{3}$

O esquema apresentado na figura 1 explicita essas ideias de Paulo Freire aplicadas à prática educativa da Enfermagem, discorrendo o enfoque da pedagogia freireana na presente pesquisa. ${ }^{1,3}$

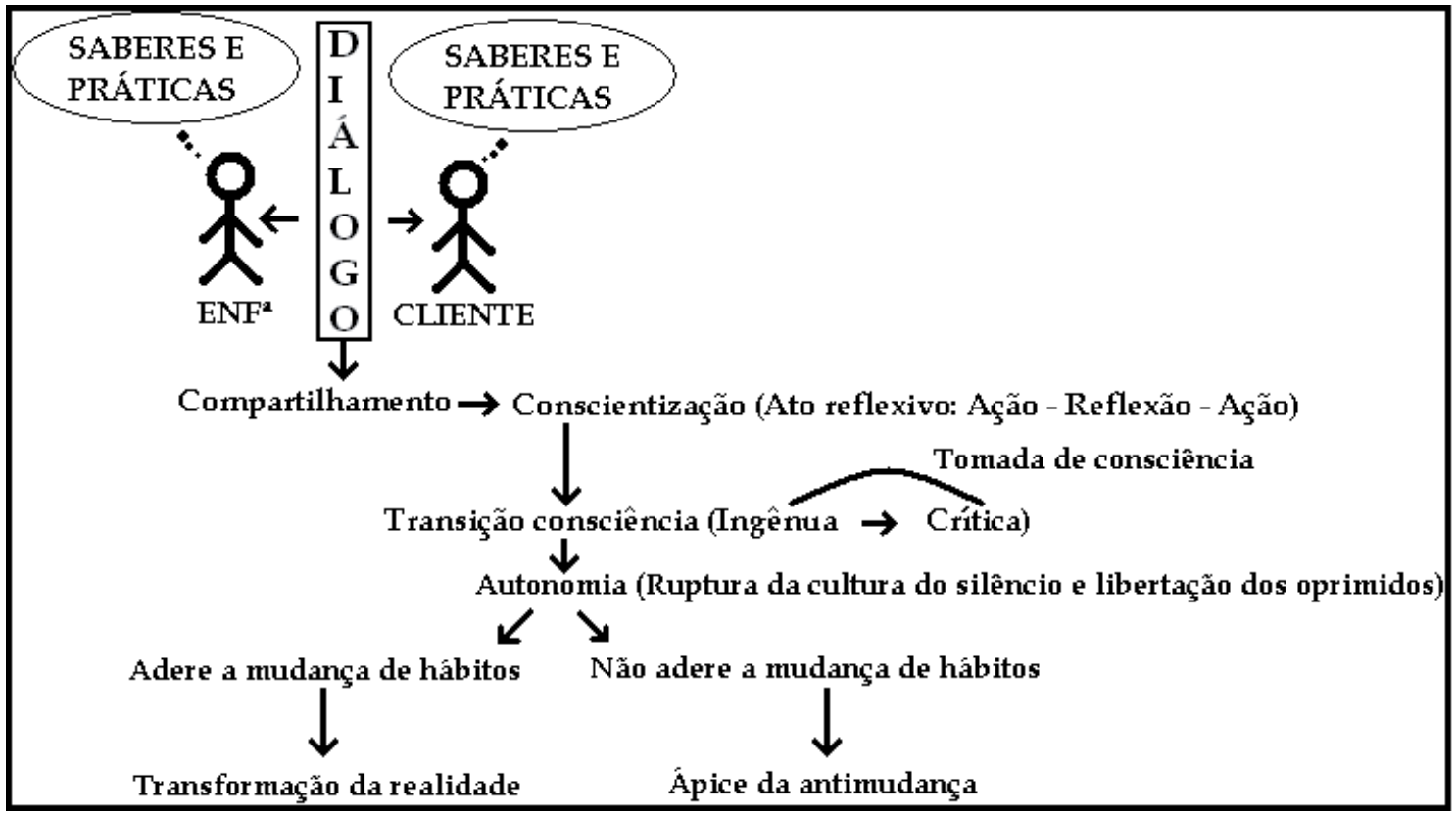

Figura 1 - Articulação entre as ideias de Freire (extraídas principalmente das obras "Pedagogia do Oprimido" e "Educação e Mudança") e a prática educativa da Enfermagem

Este estudo chama atenção às possibilidades de compartilhamento entre os saberes e práticas do sistema popular, especialmente de clientes estomizados, com o do sistema profissional, aqui representados pelo enfermeiro atuante no cuidado a estes clientes, no contexto ambulatorial. A ideia do cuidado compartilhado está amparada nos pressupostos do construcionismo social, ou seja, a construção do conhecimento dar-se-á a partir da experiência do sujeito num processo de significação. "Nesse sentido, ao pensarmos que o produto da ação de cuidar (o cuidado) pode ser compartilhado, temos aí, necessariamente, um processo dialógico permeando tal construção no encontro dos saberes - do senso comum e reificado - que, por sua vez, abarca o encontro de culturas de conhecimento e prática". 4:758 
Para isso, se faz necessário acessar os saberes e práticas de clientes estomizados sobre a manutenção da estomia de eliminação intestinal e urinária, sendo este o objeto de estudo. Isso porque, a presente proposta se reveste da compreensão do cliente como potencialmente ativo, inserido socioculturalmente em uma realidade que lhe é singular, cujas experiências se acumulam, se refazem e se modificam ao longo de sua trajetória existencial. $^{5}$

Em face dessas considerações, os objetivos da pesquisa são: conhecer o compartilhamento de saberes e práticas de clientes estomizados sobre a manutenção da estomia de eliminação intestinal e urinária no contexto ambulatorial; e discutir suas possíveis repercussões no contexto domiciliar.

\section{MÉTODO}

A abordagem metodológica escolhida foi a qualitativa. O método de pesquisa empregado foi a Pesquisa Convergente-Assistencial (PCA) ${ }^{6}$, realizada em um ambulatório público, localizado na cidade de Campos dos Goytacazes-RJ. Os sujeitos constituíram-se de 17 clientes adultos e idosos estomizados em acompanhamento ambulatorial, estando com algum tipo de estomia de eliminação intestinal e urinária (íleo/colo/urostomia); com tempo de permanência definitivo ou temporário.

O projeto foi aprovado pelo Comitê de Ética em Pesquisa da Escola de Enfermagem Anna Nery/Hospital Escola São Francisco de Assis, da Universidade Federal do Rio de Janeiro, sob o Protocolo número 052/2009, atendendo o previsto na Resolução 196/96. Os sujeitos assinaram um Termo de Consentimento Livre e Esclarecido .

O estudo foi desenvolvido em seis etapas, realizadas no período de abril de 2009 a janeiro de 2010, em dias e horários alternados, de acordo com a disponibilidade da pesquisadora e do cliente estomizado, atendendo a uma programação prévia com o mesmo ou não, captando-o, deste modo, aleatoriamente, no primeiro contato. As etapas foram ao encontro da proposta metodológica da PCA, descritas a seguir:

Fase 1 - Contato inicial com o enfermeiro e os auxiliares de enfermagem que trabalham no ambulatório, visando a imersibilidade no serviço. Este primeiro contato perdurou cerca de três meses, mais precisamente, nos meses de abril, maio e junho de 2009.

No decorrer do período de setembro de 2009 a janeiro de 2010, executou-se as fases 2, 3, 4, 5 e 6, realizadas de maneira individual. Vale mencionar que as fases 2, 3 e 4 foram efetivadas em um único encontro. Posteriormente, em um intervalo de dois a três meses, dado para a implementação do plano de cuidados compartilhado, o cliente retornou ao ambulatório para a execução das fases 5 e 6 , finalizando o processo.

Fase 2 - Inserção da pesquisadora na assistência, seguida de caracterização dos sujeitos, através de um formulário de identificação do estomizado, preenchido individualmente.

Fase 3 - Aquecimento e reflexão sobre o tema, utilizando material de auxílio, pré-confeccionado pela efermeira pesquisadora, com figuras e texto acerca do tema "manutenção da estomia de eliminação e suas complicações tardias". Em seguida, as experiências foram trocadas com os sujeitos sobre a manutenção da sua estomia de eliminação, utilizando como guia um roteiro de entrevista semiestruturada.

Fase 4 - Confecção do plano de cuidados compartilhado, à luz do que foi discutido, feito simultaneamente à fase anterior. A partir disso, os sujeitos teriam seu plano individual para a posterior execução dos cuidados de manutenção da estomia no domicílio e espaços de vida comuns.

Fase 5 - Observação participante no consultório de acompanhamento, acerca dos resultados advindos da etapa anterior, incluindo dados sobre a evolução da estomia no decorrer dos encontros, além do registro sobre a posição do cliente, assumida durante o processo de cuidado de enfermagem com a pesquisadora.

Fase 6 - Para finalizar, o sujeito foi abordado com o intuito de validar o método aplicado. Considerações sobre todo o processo foram feitas e a discussão conduzida por um roteiro de questões-chave pré-estabelecidas, gravadas em meio digital, como na terceira etapa.

Os encontros individuais para a produção de dados com os 17 sujeitos foram transcritos na íntegra, e a identificação, feita por códigos alfa-numéricos: os clientes, identificados pela letra C, e a pesquisadora, pela letra P. Após cada letra $\mathrm{C}$ inserida no texto, foram agregados números arábicos sequenciais, de acordo com a ordem de produção dos dados.

Os dados foram analisados e interpretados a partir da triangulação dos achados emergentes das técnicas de produção de dados ora apontadas, relacionando a caracterização dos sujeitos estomizados com os saberes e práticas compartilhados e 
suas repercussões, agregando as observações participantes. Assim, o processo de categorização foi iniciado, a partir da análise de conteúdo temática. ${ }^{7}$ Deste processo de categorização temática, emergiu a categoria: "O compartilhamento entre os saberes e as práticas do sistema profissional e popular sobre a manutenção da estomia de eliminação", e as subcategorias: "Da confecção à execução do plano de cuidados compartilhado"; e "Repercussões do cuidado compartilhado no contexto domiciliar".

\section{RESULTADOS E DISCUSSÃO}

\section{O compartilhamento entre os saberes e as práticas do sistema profissional e popular sobre a manutenção da estomia de eliminação}

Os saberes do sistema profissional quase sempre são instituídos como sendo os mais corretos e intransponíveis. Todavia, esses saberes nem sempre dão conta da individualidade de cada sujeito, pois são elaborados, mediante a comprovação da ciência, para um grupo específico de clientes que apresentam as mesmas situações físicas e/ou psíquicas, não dando conta, na prática, dos anseios trazidos por cada sujeito imbuído do seu contexto sociopolíticocultural. Mesmo não contemplando os sujeitos na sua totalidade, os profissionais de saúde geralmente continuam impondo o seu saber, numa relação monológica e prescritiva para com os clientes, fazendo necessária uma mudança de perspectiva no pensar e fazer da enfermeira no campo da educação popular em saúde. ${ }^{5}$

A educação popular toma como ponto de partida os saberes prévios dos educandos, construídos pelos sujeitos à medida que vão seguindo seus caminhos de vida; uma aposta pedagógica que permite a inclusão de novos atores no campo da saúde, fortalecendo a organização popular e ampliando as práticas das equipes de saúde a partir do diálogo com o saber popular. Assim, busca empreender uma relação de troca de saberes entre o saber popular e o científico, em que ambos têm a enriquecer reciprocamente. ${ }^{8}$

Propõe-se uma reorientação nas práticas de educação em saúde da enfermeira, de modo que essa atividade passe a ser uma construção conjunta com os usuários, dando ênfase à participação popular no seu cotidiano. A relação de diálogo para uma troca de saberes permitiria o surgimento de um terceiro saber, fruto da interação entre os conhecimentos dos profissionais de saúde e da população. ${ }^{8}$
Nesse sentido, a partir das vivências e experiências de clientes sobre a manutenção da estomia que se revelaram no encontro com a enfermeira construiu-se um plano de cuidados individual e congruente com as necessidades e desejos dos clientes participantes dos momentos de convergência pesquisa-cuidado. Nesta troca envolvente, emergiram práticas e saberes acerca da troca da bolsa coletora (drenável e fechada); manutenção diária da bolsa coletora drenável (uma abertura e duas aberturas); manutenção da bolsa coletora fechada; manutenção diária da bolsa coletora drenável para urostomia; autoirrigação; uso de adjuvantes (barreira potetora de pele em pasta e pó, e lubrificante desodorante); complicações tardias (dermatite, prolapso e hérnia); uso de acessórios (cinta e adesivo fixador); banho de sol (falta de privacidade para o banho de sol e falta de tempo para o banho de sol); proteção do equipamento durante o banho habitual; vida social, familiar e laborativa; religiosidade e espiritualidade; sexualidade; exercícios e desportos; lazer; direitos e deveres; vestuário e dieta.

A partir do processo de revelação desses saberes e práticas e da análise conjunta da pertinência de utilização dos mesmos pela crítica e reflexão, procurou-se pontuar os cuidados fundamentais acerca da manutenção da estomia de eliminação intestinal e urinária, à luz do que foi discutido, com a finalidade de que os mesmos pudessem ser implementados no domicílio, e trouxessem resultados satisfatórios ao serviço ambulatorial, no que tange à efetividade do cuidado de enfermagem. Para tanto, se fez oportuno conhecer as demandas de cuidados dos clientes, bem como, os elementos de cuidados oriundos do saber comum e aqueles incorporados do saber científico e reproduzidos no domicílio.

\section{Da confecção à execução do plano de cuidados compartilhado}

A confecção do plano de cuidados foi o produto instituído mediante a troca de experiências e saberes no ambulatório, tendo sido a pedagogia problematizadora instrumento facilitador na aprendizagem de clientes estomizados durante o processo educativo.

"Quando trazemos as ideias freireanas para o cotidiano da prática educativa (cuidativa) da enfermeira, podemos, pela crítica e reflexão, ver transformados ou reconstruídos saberes dentro de um grupo que não tem o conhecimento 
advindo do princípio acadêmico-científico, ao mesmo tempo em que também nos apropriamos do conhecimento que vem do universo comum. Nessa perspectiva, a pessoa tem a oportunidade de pontuar e refletir sobre os próprios veículos da educação em saúde". .:316-7

O uso da pedagogia freireana na prática educativa da rnfermagem, permite uma maior absorção do conhecimento, como: [...] a gente absorve mais coisas daquilo que a gente tem dúvida, entendeu? (C1). Uma pedagogia que revitaliza e se importa com a realidade do sujeito. Problematizando as diferentes situações que se apresentam, o cliente aguça a sua capacidade reflexiva, passando a questionar sobre o que pensa, como age e as consequências de sua ação, o que pode resultar em maior segurança para imprimir as mudanças necessárias à sua saúde e bem-estar.

O processo educativo, quando baseado na abordagem crítico-reflexiva, utiliza o diálogo como compromisso amoroso, para, através dele, acessar o universo de concepções, saberes e práticas do cliente, considerando-o como sujeito ativo deste processo. “[...] o diálogo verdadeiro pressupõe um pensar verdadeiro, um pensar crítico, pensar que percebe a realidade como processo" ${ }^{\prime: 119}$ Faz-se necessário , para tanto, estabelecer uma relação dialógica horizontal com o cliente, nutrida pelo amor, humildade, esperança, fé e confiança. Instala-se uma empatia entre ambos para se fazerem críticos, havendo a comunicação. ${ }^{10}$ Essa investida, ao tempo em que viabiliza ao enfermeiro penetrar no universo cultural do estomizado, trocando vivências e experiências, o torna receptivo às mudanças que porventura emerjam. Há de salientar nesse ínterim a adequação da linguagem à realidade de cada sujeito, considerando sua inserção sociocultural.

A co-participação no processo educativo se dá pelo entrelace das informações advindas do compartilhamento entre enfermeira-cliente, um ajudando o outro, onde sobressaem dicas da enfermeira e do cliente, na constante procura de um consenso sobre o cuidado a ser instituído: [...] você deu algumas dicas pra estar colocando em prática e isso foi positivo pra mim [...] (C2). Afinal, a educação à saúde se contrói "com" o outro e não "para" o outro, o que implica em uma relação horizontal e recíproca em que ambos se beneficiem, uma vez interessados na aprendizagem conjunta e na coconstrução do cuidado. Nesse sentido, a educação compreendida como ato coletivo, não pode ser imposta, justamente por pressupor troca entre pessoas. Assim, sempre haverá partes de um e de outro. Do mesmo modo, pensar em cuidado compartilhado implica em abertura ao debate, em estar receptivo às outras possibilidades de cuidar do outro e de si. A busca pelo cuidado do próprio corpo é gratificante, mas é algo que demanda tempo e requer dedicação.

Nessa perspectiva, cabe à enfermagem valorizar a subjetividade do cliente estomizado, centrando-se no diálogo com o sujeito, a partir do reconhecimento que este ser humano é o único conhecedor da situação vivida. Para fomentar o cuidado de si, a enfermeira deve auxiliá-lo, respeitando a sua vivência, nos cuidados a sua saúde, tendo como meta uma melhoria da sua qualidade de vida. ${ }^{11}$

C7 ressalta o quanto é bom ter uma pessoa para compartilhar o cuidado e que a experiência dos nossos encontros na convergência pesquisa-cuidado foi fundamental para sua aprendizagem e autoconfiança: [...] com a sua experiência, eu acho que eu aprendi muito. Foi muito bom mesmo pra mim, nossa! A gente conversou com uma pessoa que tem experiência. A gente fica mais confiante!

O diálogo como instrumento facilitador do processo educativo foi-se revelando como fundamental no alcance do cuidado compartilhado: [...] e você foi me dando mais algumas dicas [...] (C2). Associados à prática dialógica, outros recursos de aprendizagem foram sendo incorporados a este processo como a disposição do material sobre a mesa, utilizado para o cuidado de si.

A educação em saúde pautada em princípios da problematização se coloca em contraposição à pedagogia tradicional, hierarquizada, quase sempre prescritiva, monológica. O alcance da crítica-reflexão acerca do cuidado possibilita agora uma autonomia plena e não mais a execução de práticas fragmentadas, de quem segue o que está prescrito pelo profissional sem refletir criticamente sobre o uso de determinada prática:

[...] ajudou também nos pequenos detalhes, a gente fica mais atenta as ações da gente, do dia a dia (C1).

[...] eu gostei porque me capacitou mais [...] (C9).

[...] eu fazia porque era o dia a dia, é aquele costume do dia a dia, eu fazia daquele jeito porque era o dia a dia que a gente tinha assim, já tinha aprendido daquela forma e fazia do dia a dia, mas sem uma experiência, sem uma inovação, quer dizer, teve uma outra oportunidade como deve ser feito também agora [...] (C10).

[...] comecei a refletir melhor sim, pensar no tratamento mais adequado (C12).

Da crítica-reflexiva possibilitada pelo diálo- 
go problematizador nos encontros de pesquisa-cuidado, extraiu-se demandas de aprendizagem. Essas demandas emergiram do compartilhamento de saberes e práticas do sistema popular e profissional entre mim, enfermeira, e os clientes estomizados. Criticizando a própria prática de se cuidar, fruto de práxis existencial, estes clientes foram experimentando novas maneiras de agir frente à sua estomia, refletindo e executando cuidados que são fundamentais à sua manutenção. Gradativamente, à medida que avança sua condição de crítica e de reflexão, os clientes aguçam sua capacidade não somente de executar, mas de avaliar o cuidado realizado de maneira ímpar, o que torna sua ação mais autônoma. "[...] no instante em que o educador reconhece a vocação ontológica do ser-sujeito histórico, temporal, criativo e cultural, utiliza a educação para a transformação e autonomia do educando, isto é, para ser mais". 12:635

Quando se pensa no alcance da autonomia desses clientes, possibilitada pelo diálogo transformador, a cultura do silêncio se rompe, libertando os oprimidos até então "coisificados" pela ação profissional. Vale lembrar que "o homem deve ser o sujeito de sua própria educação. Não pode ser o objeto dela. Por isso, ninguém educa ninguém" ${ }^{3: 28}$ Como sujeito cognoscente, imerso no mundo e com o mundo, ele deve ser reconhecido e ouvido por meio de um processo de educação estabelecido numa relação horizontal e recíproca através do diálogo que comunica. A partir deste método participativo, dialogal e ativo, que permite a comunicação, ambos se educam em comunhão, mediatizados pelo mundo. É possível, assim, transformar a realidade, na medida em que facilita a aprendizagem, no caso ora apreciado, dos clientes estomizados no contexto ambulatorial de cuidado:

[...] depois que eu conversei com você, você me instruiu e graças a Deus deu tudo certinho! (C6).

Assim, de passivo, o cliente se torna ativo e coparticipa do seu próprio cuidado, avaliando o uso ou não de práticas relacionadas ao seu estoma: [...] é muito bom isso [...] ainda mais para uma pessoa fechada como eu, entrei aqui e saí falando tudo [...]. (C9). A prática educativa implementada, alicerçada nos princípios da problematização fez a diferença e assim foi avaliada positivamente pelos clientes participantes da pesquisa.

A capacidade de ouvir do enfermeiro também foi relacionada ao uso da pedagogia problematizadora. A observação sobre a escuta sensível por parte do enfermeiro é importante, pois colabora na expressão de sentimentos dos clientes sobre as questões que envolvem a convivência com o estoma. Para ouvir o outro é necessária disponibilidade pessoal, estar atenta aos seus sentimentos e maneira pela qual os clientes esperam serem cuidados. Quando se imprimem qualidades expressivas no cuidado, a enfermeira não mais realiza procedimentos em alguém, mas reflete junto e realiza uma ação integrada, com envolvimento e responsabilidade; proporciona, assim, crescimento para ambos os envolvidos na relação do cuidado. ${ }^{13}$ A premissa básica daqueles que realizam o processo educativo é proporcionar o fortalecimento pessoal dos seres humanos com quem interagem, é ajudá-los a ajudar-se, fazê-los agente de sua transformação. ${ }^{3}$ Desta feita, através do processo educativo implementado foi possível alcançar resultados favoráveis:

[...] não senti dificuldade nenhuma, aprendi logo, aprendi bem, não senti dificuldade não e até pratiquei mais rápido $(\mathrm{C} 12)$.

[...] isso é bom, porque todo lugar que faz isso [educação em saúde centrado no diálogo] relata coisa evoluída, de evolução melhor pra gente (C14).

Uma pedagogia que além de facilitar a aprendizagem, melhora a confiança do cliente acerca do cuidado, sendo fundamental à sua qualidade: [...] porque eu aprendi mais, aprendi mais, fiquei assim, acreditando mais em mim! Isso eu acho que foi o mais importante, eu acreditar em mim! Eu não sabia mesmo como fazer aquilo! Fez uma diferença enorme em mim! (C7). Proporcionar uma relação de participação e reciprocidade aumenta às possibilidades de estabelecimento de vínculos frente aos limites apresentados, e isto se torna viável através de uma relação dialógica, processada horizontalmente. Caso contrário, diante de um anti-diálogo, em uma relação vertical, as pessoas se tornam inseguras, incapazes de tomar decisões. ${ }^{14}$

Assim, o plano de cuidados compartilhado resultou do diálogo problematizador que levou cada cliente a revisitar seus saberes e práticas sobre a manutenção da estomia e abrir-se às novas maneiras de se cuidar.

\section{Repercussões do cuidado compartilhado no contexto domiciliar}

O compartilhamento das informações entre enfermeira-cliente no contexto ambulatorial, pautado pela pedagogia problematizadora, se revelou pertinente, na medida em que facilitou a aprendizagem dos clientes estomizados acerca da 
manutenção da estomia de eliminação. Por conseguinte, contribuiu com o cuidado de enfermagem no contexto ambulatorial, resultando em sua maior efetividade:

[...] é, foi muito importante né, porque a gente acha que tá agindo de uma maneira correta e a ajuda de um profissional é bem gratificante né, que passa a ter observação, que passa a observar mais, né? Ter aqueles cuidados, mas redobra os cuidados porque tem detalhes que as pessoas nem percebem e uma conversa profissional a gente já vai avaliando com mais [...]. Com mais cuidado, né, com mais atenção, mais atenção naquele processo. Foi muito bom, gostei (C1).

O cliente passa a refletir e a atentar sobre cuidados que são essenciais à manutenção de sua estomia, como a higiene. Além disso, o que, a priori, foi apresentado como problema pelo cliente ou pela enfermeira durante o processo de educação em saúde realizada no ambulatório, após a implementação de práticas no contexto domiciliar instituídas no plano de cuidados co-construído, em grande parte, no retorno do cliente ao ambulatório, foi possível se desvelarem as transformações positivas ocorridas face ao cuidado compartilhado.

Um exemplo é a melhoria da dermatite, em que a cliente, por conta disso, também, está mantendo por mais dias a bolsa coletora. Durante a troca de saberes estabelecida, a enfermeira pesquisadora indaga sobre os detalhes do cuidado estabelecido no domicílio e é justamente aí que se revelam as possibilidades de mudança de hábitos frente às dificuldades e problemas encontrados. Isto porque, consciente de sua condição e do cuidado necessário à manutenção de sua estomia, 0 cliente reúne melhores possibilidades de cuidar de si no domicílio. Para a enfermeira, tal evento se reveste de uma avaliação positiva acerca do cuidado implementado e dos instrumentos utilizados para a sua efetivação, como foi o caso do cuidado compartilhado utilizando a pedagogia problematizadora:

[...] todo o ensinamento que eu aprendi aqui, posso dizer que eu me sinto mais profissional no que tange ao meu ostoma (C4).

[...] ahã, entendi. Com mais autonomia, vamos dizer assim, em relação ao seu cuidado. Consegue avaliar, né?! (P).

\section{[...] mais maturidade, né?! (C4).}

A prática dialógica traz para o contexto do cuidado a condição de crítica e de reflexão do cliente que, por sua vez, permite a tomada de consciência sobre o problema e a possibilidade de agir sobre ele de modo a transformá-lo. ${ }^{5}$ Uma vez consciente, o cliente se torna mais ativo e partícipe do cuidado; sente-se mais seguro para exercer sua autonomia neste processo, o que o habilita a avaliar os cuidados prestados no domicílio.

A segurança sentida diante de um resultado positivo contribuiu com a reinserção social de C5: [...] porque antigamente eu botava a bolsa e rapidamente eu sentia que a bolsa, que a cola estufava. Então, quer dizer, aquilo ia acontecendo e eu não tinha coragem de sair pela rua [...]. Agora, não, se for até pra eu ir viajar, alguém me chamar pra eu ir pro Rio, pra casa de parente, eu vou! Porque eu vou me sentir seguro! Porque antigamente pra eu ir num lugar distante ou entrar num carro, poderia a qualquer momento, soltar minha bolsa. Antigamente ela começava a vazar e eu nem percebia aquilo e quando via, estava tudo molhado! (C5).

Outra cliente que não conseguia realizar a troca da bolsa coletora, sendo o procedimento feito pela cunhada, após o plano de cuidados compartilhado, está fazendo todos os cuidados de manutenção, inclusive colar a bolsa, não dependendo de outra pessoa para fazê-los. Disse que com a nossa "conversa", criou coragem, foi criando coragem..., E expressou: [...] um alívio! (C7) Com a independência, a cliente se insere novamente na sociedade e se sente mais segura quando usa o adesivo fixador.

C5 passou ainda a usar sabonete para a higienização durante a troca da bolsa coletora, e C6 parou de retirar a cola bruscamente, durante o descolamento da bolsa, e, ainda, passou a medir sempre antes de recortar a placa.

Ainda relacionado ao recorte da bolsa, C7 transformou a sua realidade, medindo sempre antes de recortar e colar, ocasionando um recorte rente ao estoma. Também, ao aprender sobre este cuidado, procurou orientar sua acompanhante que, até então, ainda era a principal responsável pelos cuidados ao estoma do cliente. Destaca-se que esta relação de dependência também se modificou.

Além disso, a indicação do pó cicatrizante e o seu uso de forma apropriada ajudaram na cicatrização da dermatite e, ainda, no alcance da independência para a troca da bolsa:

[...] me ajudou no recorte, me ajudou a colocar esse pozinho que me ajudou na cicatrização, né! [...] Eu acho que valeu muito! (C7).

C5 passou a retirar o excesso do pó cicatrizante, que causava a não adesão da bolsa coletora à pele. Ao conhecer o lubrificante desodorante, C14 
considerou que poderia utilizá-lo no seu domicílio e assim o levou para efeito comprobatório:

[...] é depois de usar esse produto aí, a solução, melhorou mais, pelo menos isso, além do que a gente [...]. Não era repassado e, às vezes, a gente pensava que a bolsa estava limpa e não estava, às vezes, as fezes grudavam aqui do lado e era ruim pra sai; com ela não, só sacode um pouquinho e quando vai ver, a água fica bem limpa $[\ldots](\mathrm{C} 14)$.

Isso mostra que o estímulo ao conhecimento do novo deve ser feito pelo enfermeiro no ambulatório, considerando, no entanto, a pertinência de cada caso aplicada à realidade. $\mathrm{C} 4$ passou a se cuidar melhor e, agora, não mais utiliza o éter que passava há anos em sua pele para a retirada facilitada da bolsa coletora:

[...] olha, contribuiu porque aquilo que eu descuidava um pouquinho, passei a cuidar mais, né. Tipo assim: Eu falei da outra vez que eu costumava usar um éter para soltar melhor a parte da cola e a senhora me informou que aquilo é prejudicial, não faz bem a pele... e eu passei a não usar mais e tô sentindo que a situação é essa mesmo... realmente o éter não foi feito pra isso... que é uma falha nossa querer às vezes uma coisa mais rápida, mas que prejudica (C4).

Já para C5 a experiência do cuidado compartilhado, na sua avaliação, melhorou sua autoestima e sua reinserção social:

[...] minha autoestima também até levantou melhor porque agora já estou saindo de casa [...] até na minha autoestima contribuiu. Contribuiu muito, melhorou muito. Antigamente assim eu não tinha, eu saía daqui e meu negócio era ficar em casa, preso. Não saía nem no portão. Me sentia pior que um prisioneiro, porque prisioneiro ainda toma banho de sol [...] (C5).

$\mathrm{O}$ aumento na qualidade de vida a partir da prática correta de manutenção da estomia no domicílio também foi ressaltado:

[...] eu gostei. Foi muito bom porque eu parei pra refletir algumas coisas que eu tava fazendo. Porque às vezes a gente acha que tá fazendo correto por causa da prática da gente, e aí não é. E pra gente ter melhor qualidade de vida, é melhor a gente fazer correto (C8).

A educação em saúde revelou-se como uma chave para o sucesso na convivência do cliente com o estoma. Esse cliente, consciente dos seus limites e possibilidades para o cuidado de manutenção da sua estomia de eliminação, torna-se um aliado na relação de cuidado. Verificam-se que as alterações ocasionadas pela confecção do estoma perpassam as dimensões física, mental e socioeconômica na vida do portador de estomia. No entanto, o mesmo deve lidar com a nova condição de saúde de maneira otimista sendo necessária uma colaboração multidisciplinar para promover a sua reabilitação e melhora da qualidade de vida. ${ }^{15}$

Pode-se perceber nos exemplos relatados que a repercussão dos cuidados no contexto domiciliar foi de grande relevância, na medida em que possibilitou contribuições notórias ao cuidado e à evolução da estomia em si. $\mathrm{O}$ alcance da autonomia planejada se tornou real, e assim, facilitou os diversos cuidados executados no contexto domiciliar pelos clientes estomizados. A proposta de educação pôde "[...] ser entendida como forma de compreender o mundo, refletir sobre ele, transformando a realidade a partir de uma ação consciente" ${ }^{12: 634}$

A confecção do plano de cuidados compartilhado foi concluída na intencionalidade de promover mudanças ou minimizar problemas, o que foi verificado na libertação dos clientes oprimidos, evidenciando o comprometimento com a melhoria direta do contexto social pesquisado.

\section{CONCLUSÕES}

Nesta pesquisa, a pedagogia freireana revelou-se como um instrumento facilitador na aprendizagem de clientes estomizados no âmbito de uma proposta educativa do cuidado de enfermagem no contexto ambulatorial. Problematizando as diferentes situações que se lhes apresentam na convivência com a estomia de eliminação, os clientes foram levados a refletir sobre sua realidade através da prática dialógica implementada na convergência pesquisa-cuidado.

Com o retorno dos clientes no ambulatório, após a implementação do cuidado compartilhado, foi possível denotar os sucessos derivados da pedagogia utilizada no processo educativo. Sua condição de crítica e de reflexão está aguçada; exercendo com maior segurança e autonomia os cuidados relacionados à manutenção de sua estomia, avaliando, modificando hábitos, transformando a realidade.

Quando se trata da repercussão do estudo para o serviço, encontramos limites relativos à efetivação desse princípio, pois dificuldades de operacionalização surgiram relacionadas ao não vinculamento das pesquisadoras ao cenário pesquisado, apesar da imersibilidade na assistência no período de produção de dados, além da ausência do enfermeiro nas atividades semanais que prejudicou sua participação e comunicação com a 
enfermeira-pesquisadora. No entanto, a pesquisa demonstrou que é possível a transformação de sujeitos face à utilização da proposta educativa do cuidado de enfermagem no contexto ambulatorial.

O debate acerca de uma proposta educativa do cuidado de enfermagem no contexto ambulatorial é evidenciado na pesquisa, revelando uma diretriz sobre como, efetivamente, os enfermeiros podem executar essa atividade precípua junto a clientes estomizados. No entanto, ainda carecemos de estudos que explicitem uma tecnologia de processo educativo em saúde aplicada à diferentes contextos e grupos sociais.

\section{REFERÊNCIAS}

1. Freire P. Pedagogia do oprimido. $45^{\mathrm{a}}$ ed. São Paulo (SP): Paz e Terra; 2006.

2. Oliveira CAGS, Rodrigues JC, Silva KN. Identificação do nível de conhecimento de pacientes com colostomias para a prevenção de possíveis complicações. Rev Estima. 2007; 5(4):26-30.

3. Freire P. Educação e mudança. $31^{a}$ ed. São Paulo (SP): Paz e Terra; 2007.

4. Teixeira MLO, Ferreira MA. Cuidado compartilhado: uma perspectiva de cuidar do idoso fundamentada na educação em saúde. Texto Contexto Enferm. 2009 Out-Dez; 18(4):750-8.

5. Alvim NAT, Ferreira MA. Perspectiva problematizadora da educação popular em saúde e a enfermagem. Texto Contexto Enferm. 2007 AbrJun; 16(2):315-9.
6. Trentini M, Paim L. Pesquisa convergenteassistencial: um desenho que une o fazer e o pensar na prática assistencial em saúde-enfermagem. $2^{\mathrm{a}} \mathrm{ed}$. Florianópolis (SC): Insular; 2004.

7. Bardin L. Análise de conteúdo. Lisboa (PT): Edições 70; 2002.

8. Gomes LB, Merhy EE. Compreendendo a educação popular em saúde: um estudo na literatura brasileira. Cad Saúde Pública. 2011 Jan; 27(1):7-18.

9. Acioli S. A prática educativa como expressão do cuidado em Saúde Pública. Rev Bras Enferm. 2008 Jan-Fev; 61(1):117-21.

10. Freire P. Educação como prática da liberdade. $30^{a}$ ed. Rio de Janeiro (RJ): Paz e Terra; 2007.

11. Silva IJ, Oliveira MFV, Silva SED, Polaro SHI, Radunz V, Santos EKA, et al. Cuidado, autocuidado e cuidado de si: uma compreensão paradigmática para o cuidado de enfermagem. Rev Esc Enferm USP. 2009 Set; 43(3):697-703.

12. Miranda KCL, Barroso MGT. A contribuição de Paulo Freire à prática e educação crítica em enfermagem. Rev Latino-am Enfermagem. 2004 Jul-Ago; 12(4):631-5.

13. Waldow VR. Cuidado humano: o resgate necessário. $2^{\mathrm{a}}$ ed. Porto Alegre (RS): Sagra Luzzato; 1999.

14. Fontes CAS, Alvim NAT. A relação humana no cuidado de enfermagem junto ao cliente com câncer submetido à terapêutica antineoplásica. Acta Paul Enferm. 2008 Jan-Mar; 21(1):77-83.

15. Sardiñas CLN, Alfonso LEA, Sosa MF, Arbona FLV, Martínez MLR. Problemática actual del paciente con ostomía. Rev Cubana Med Milit. 2001; 30(4):256-62. 